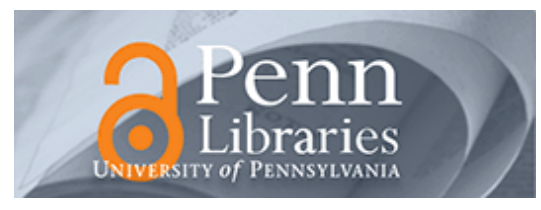

University of Pennsylvania

ScholarlyCommons

\title{
Prospective Evaluation of Sedation-Related Adverse Events in Pediatric Patients Ventilated for Acute Respiratory Failure
}

\author{
Mary Jo C. Grant \\ Lisa A. Scoppettuolo \\ Martha A. Q. Curley \\ University of Pennsylvania, curley@nursing.upenn.edu
}

Follow this and additional works at: https://repository.upenn.edu/nrs

Part of the Critical Care Nursing Commons, and the Pediatric Nursing Commons

\section{Recommended Citation}

Grant, M. C., Scoppettuolo, L. A., \& Curley, M. A. (2012). Prospective Evaluation of Sedation-Related Adverse Events in Pediatric Patients Ventilated for Acute Respiratory Failure. Critical Care Medicine, 40 (4), 1317-1323. http://dx.doi.org/10.1097/CCM.0b013e31823c8ae3

This paper is posted at ScholarlyCommons. https://repository.upenn.edu/nrs/20

For more information, please contact repository@pobox.upenn.edu. 


\title{
Prospective Evaluation of Sedation-Related Adverse Events in Pediatric Patients Ventilated for Acute Respiratory Failure
}

\author{
Abstract \\ Objectives: Sedation-related adverse events in critically ill pediatric patients lack reproducible operational \\ definitions and reference standards. Understanding these adverse events is essential to improving the \\ quality of patient care and for developing prevention strategies in critically ill children. The purpose of this \\ study was to test operational definitions and estimate the rate and site-to-site heterogeneity of sedation- \\ related adverse events. \\ Design: Prospective cohort study. \\ Setting: Twenty-two pediatric intensive care units in the United States enrolling baseline patients into a \\ prerandomization phase of a multicenter trial on sedation management. \\ Patients: Pediatric patients intubated and mechanically ventilated for acute respiratory failure. \\ Data Extraction: Analysis of adverse event data using consistent operational definitions from a Web- \\ based data management system. \\ Measurements and Main Results: There were 594 sedation-related adverse events reported in 308 \\ subjects, for a rate of 1.9 adverse events per subject and 16.6 adverse events per 100 pediatric intensive \\ care unit days. Fifty-four percent of subjects had at least one adverse event. Seven (1\%) adverse events \\ were classified as severe, $347(58 \%)$ as moderate, and 240 (40\%) as mild. Agitation (30\% of subjects, $41 \%$ \\ of events) and pain ( $27 \%$ of subjects, $29 \%$ of events) were the most frequently reported events. Eight \\ percent of subjects $(n=24)$ experienced 54 episodes of clinically significant iatrogenic withdrawal. \\ Unplanned endotracheal tube extubation occurred at a rate of 0.82 per 100 ventilator days, and 32 \\ subjects experienced postextubation stridor. Adverse events with moderate intraclass correlation \\ coefficients included: Inadequate sedation management (intraclass correlation coefficient $=0.130$ ), \\ clinically significant iatrogenic withdrawal (intraclass correlation coefficient $=0.088$ ), inadequate pain \\ management (intraclass correlation coefficient $=0.080$ ), and postextubation stridor (intraclass correlation \\ coefficient $=0.078$ ). \\ Conclusions: Operational definitions for sedation-related adverse events were consistently applied across \\ multiple pediatric intensive care units. Adverse event rates were different from what has been previously \\ reported in single-center studies. Many adverse events have moderate intraclass correlation coefficients, \\ signaling site-to-site heterogeneity.

\section{Disciplines} \\ Critical Care Nursing | Medicine and Health Sciences | Nursing | Pediatric Nursing
}


Published in final edited form as:

Crit Care Med. 2012 April ; 40(4): 1317-1323. doi:10.1097/CCM.0b013e31823c8ae3.

\title{
Prospective evaluation of sedation-related adverse events in pediatric patients ventilated for acute respiratory failure
}

\author{
Mary Jo C. Grant, PNP-AC, PhD, FAAN, Lisa A. Scoppettuolo, MS, David Wypij, PhD, \\ Martha A. Q. Curley, RN, PhD, FAAN, and for the RESTORE Investigative Team \\ Pediatric Critical Care (MCG), Primary Children's Medical Center, Salt Lake City, UT; Department \\ of Cardiology (LAS, DW), Children's Hospital Boston, Boston, MA; and School of Nursing, \\ Anesthesia and Critical Care Medicine (MAQC), University of Pennsylvania, Philadelphia, PA.
}

\section{Abstract}

Objectives-Sedation-related adverse events in critically ill pediatric patients lack reproducible operational definitions and reference standards. Understanding these adverse events is essential to improving the quality of patient care and for developing prevention strategies in critically ill children. The purpose of this study was to test operational definitions and estimate the rate and site-to-site heterogeneity of sedation-related adverse events.

Design-Prospective cohort study.

Setting-Twenty-two pediatric intensive care units in the United States enrolling baseline patients into a prerandomization phase of a multicenter trial on sedation management.

Patients-Pediatric patients intubated and mechanically ventilated for acute respiratory failure.

Data Extraction-Analysis of adverse event data using consistent operational definitions from a Web-based data management system.

Measurements and Main Results-There were 594 sedation-related adverse events reported in 308 subjects, for a rate of 1.9 adverse events per subject and 16.6 adverse events per 100 pediatric intensive care unit days. Fifty-four percent of subjects had at least one adverse event. Seven $(1 \%)$ adverse events were classified as severe, $347(58 \%)$ as moderate, and $240(40 \%)$ as mild. Agitation ( $30 \%$ of subjects, $41 \%$ of events) and pain ( $27 \%$ of subjects, $29 \%$ of events) were the most frequently reported events. Eight percent of subjects $(n=24)$ experienced 54 episodes of clinically significant iatrogenic withdrawal. Unplanned endotracheal tube extubation occurred at a rate of 0.82 per 100 ventilator days, and 32 subjects experienced postextubation stridor. Adverse events with moderate intraclass correlation coefficients included: inadequate sedation management (intraclass correlation coefficient $=0.130$ ), clinically significant iatrogenic withdrawal (intraclass correlation coefficient $=0.088$ ), inadequate pain management (intraclass correlation coefficient $=$ 0.080 ), and postextubation stridor (intraclass correlation coefficient $=0.078$ ).

Copyright (9) 2012 by the Society of Critical Care Medicine and Lippincott Williams \& Wilkins

For information regarding this article, maryjo.grant@imail.org

The authors have not disclosed any potential conflicts of interest. 
Conclusions-Operational definitions for sedation-related adverse events were consistently applied across multiple pediatric intensive care units. Adverse event rates were different from what has been previously reported in single-center studies. Many adverse events have moderate intraclass correlation coefficients, signaling site-to-site heterogeneity.

\section{Keywords}

adverse events; children; intensive care unit; medical errors; patient safety; sedation

Patient safety is recognized as a healthcare priority deserving concentrated efforts aimed at reducing system failures and errors that lead to preventable adverse events (AEs) and injury. Identifying preventable errors may be especially important in critically ill children (1-3). Iatrogenic illness has been identified in $62 \%$ of pediatric intensive care unit (PICU) admissions for a rate of 28.6 AEs per 100 patient days (4).

Pediatric patients admitted to the intensive care unit are at risk for AEs because of the criticality and complexity of their care. Examples of AEs include transient hypoxemia, pain, agitation, sleep pattern disturbance, nosocomial infection, gastrointestinal bleeding, intolerance of gastric feeding, and skin breakdown. Standards of PICU care focus on using evidence-based practice to prevent these AEs.

Pediatric patients with acute respiratory failure supported on mechanical ventilation require PICU care and receive concomitant sedation to prevent complications associated with ventilator management. Pediatric sedation may be inherently unique because of characteristics of the pediatric population, including small size and cognitive immaturity (1). Surveillance and prevention of iatrogenic events in critically ill pediatric patients requires the consistent use of terms and vigilance within PICUs and benchmarking across PICUs. Understanding the epidemiology of AEs related to sedation management may facilitate the development of prevention strategies in this specific patient population. The purpose of this observational study was to test operational definitions and estimate the rate and site-to-site heterogeneity of prospectively collected sedation-related AEs in pediatric patients intubated and mechanically ventilated for acute respiratory failure at 22 PICUs.

\section{MATERIALS AND METHODS}

We conducted a review of observational data prospectively collected from all 308 pediatric subjects enrolled in the baseline, prerandomization phase of a multicenter trial on sedation management in patients with acute respiratory failure titled Randomized Evaluation of Sedation Titration fOr Respiratory FailurE (RESTORE). Twenty-two PICUs of varying size and organizational structure located in the United States contributed to the data set. During the baseline, prerandomization phase of the RESTORE trial, all subjects received usual care. Patient sedation and pain control was managed at the discretion of the care team and no recommendations were made by the RESTORE team.

The inclusion and exclusion criteria established for the RESTORE trial were used. We studied pediatric patients aged $\geq 2$ wks and $<18$ yrs who were intubated and mechanically ventilated for acute pulmonary airways or parenchymal disease. We only enrolled full-term 
infants $\geq 42 \mathrm{wks}$ postmenstrual age and did not enroll patients from neonatal intensive care units to avoid known differences in neonatal physiology. Patients were most frequently excluded if they had cyanotic heart disease, were ventilated for immediate postoperative care or neuromuscular respiratory failure, had a critical airway, or had participated in other pediatric critical care clinical trials within the preceding 30 days.

Each PICU provided approximately 3 months of data between January and July 2009. Data were collected for each subject from endotracheal intubation until $72 \mathrm{hrs}$ after their last opioid dose, hospital discharge, or day 28 , whichever occurred first. The study was approved by the institutional review board at each institution. All sites completed an organizational assessment before data collection and reported typical U.S. practice patterns of no more than two patients per nurse.

Subjects were monitored daily for the occurrence of events defined as any undesirable experience or unanticipated benefit. All data were entered into a Web-based data management system. The manual of operations describing standard operating procedures for data collection helped to ensure consistent decision making across clinical sites. Each site reviewed the medical records of a randomly selected subset of two or three subjects to evaluate potential under-reporting of AEs.

AEs are defined as any untoward or unfavorable medical occurrence, including any abnormal sign (for example, abnormal physical exam or laboratory finding), symptom, or disease that is specified in the protocol (RESTORE Specified Event) or different from what is expected in the clinical course of a critically ill pediatric patient with acute lung disease supported on mechanical ventilation, and may be related to sedation management. Sedationrelated AEs typically occurring in pediatric intubated patients were identified through an exhaustive systematic review of the literature and designated as RESTORE Specified Events. Site coinvestigators were provided operational definitions for each RESTORE Specified Event (Table 1). Site coinvestigators, research assistants, and data extractors received oneon-one training on the standard operating procedure of reporting and grading the severity of RESTORE Specified Events. Training was reinforced during monthly Steering Committee conference calls.

The severity of an $\mathrm{AE}$ was defined in the manual of operations as a qualitative assessment of the degree of intensity of the event as determined initially by bedside clinicians then verified by site coinvestigators as follows: 1) mild: does not impact (in any way) the patient's course of illness; 2) moderate: impacts the subject's course of illness but is not life threatening or incapacitating; or 3) severe: fatal, life threatening, severely incapacitating, permanently disabling, or requires/prolongs inpatient hospitalization.

A baseline assessment was completed on all subjects, including demographic data, medical history information, and primary cause for acute respiratory failure. Cognitive development and functional health were measured by the Pediatric Cerebral Performance Category and Pediatric Overall Performance Category (POPC) (5). Pediatric Risk of Mortality III-12 (PRISM III-12) scores were calculated using data collected within $12 \mathrm{hrs}$ of PICU admission (6). 
Throughout the subject's course, we collected information on sedation administered as well as levels of pain, agitation, and withdrawal. All pain assessment tools were based on a 10point scale. The pain assessment tool depended upon the age and verbal capacity of the subject: infant to 7 yrs and nonverbal: Facial expression, Leg movement, Activity, Cry, and Consolability $(7,8) ; 3+$ yrs of age and verbal: Wong-Baker FACES $(9) ; 5+$ yrs of age and verbal: Numeric Rating Scale; and $\geq 8$ yrs and nonverbal: Individualized Numeric Rating Scale (10). The sedation-agitation spectrum was monitored using the validated State Behavioral Scale (SBS) (11). Clinicians used their clinical judgment to identify pain and/or agitation in patients requiring neuromuscular blockade, such as "assumed pain present" and/or "assumed agitation present" when the patient experienced $>20 \%$ increase in heart rate/blood pressure when stimulated. The Withdrawal Assessment Tool-Version 1 was used to assess opioid withdrawal (12) in patients weaning from at least 5 days of opioids. The presence and intensity of withdrawal symptoms were assessed at least every $12 \mathrm{hrs}$. After baseline training, each clinical team provided five sets of paired SBS and Withdrawal Assessment Tool-Version 1 ratings. Inter-rater reliability on the SBS and Withdrawal Assessment Tool-Version 1 was then maintained at $>80 \%$. Given the lack of validated instruments in the pediatric population, there was no systematic assessment of delirium.

The rate of unplanned endotracheal tube (ETT) extubation was defined as events per 100 ventilator days. The rate of unplanned removal of any invasive tube, excluding ETTs, was defined as events per 100 device days. Device days included all days with any invasive catheter/tube through study discharge, and subjects could contribute multiple device days on the same study day.

Ventilator-associated pneumonia (VAP) was defined as pneumonia occurring $\geq 48 \mathrm{hrs}$ after the initiation of mechanical ventilation (13), and the VAP rate as the number of VAP per 1000 ventilator days. Ventilator days were defined as all days intubated (days on ventilator for patients with tracheostomy) through study discharge. The catheter-associated bloodstream infection (CA-BSI) rate was reported as infections per 1,000 central catheter days. The National Nosocomial Infections Surveillance System definitions were used for VAP and CA-BSI (14). All VAP and CA-BSI were adjudicated by the local infectious disease officer using a standardized process (15). Pressure ulcers were staged according to the National Pressure Ulcer Advisory Panel recommendations (16) and attribution assigned using the Braden Q scale (17).

Duration of mechanical ventilation was defined as the number of days from intubation until the first time the ETT was continuously absent for at least 24 hrs. For subjects with a tracheostomy, duration of mechanical ventilation was defined as the number of days from the initiation of pressure support $25 \mathrm{~cm} \mathrm{H}_{2} \mathrm{O}$ (i.e., ventilator, bilevel positive airway pressure, Vapotherm, or continuous positive airway pressure $25 \mathrm{~cm} \mathrm{H}_{2} \mathrm{O}$ ) until the first time pressure support $\geq 5 \mathrm{~cm} \mathrm{H}_{2} \mathrm{O}$ was discontinued for at least $24 \mathrm{hrs}$.

PICU length of stay was defined as the time from PICU admission to PICU discharge and was censored at day 28 for subjects in the PICU for $>28$ days or subjects who were transferred out of the hospital. Acute lung injury and acute respiratory distress syndrome were defined as the acute onset of respiratory distress and bilateral infiltrates/opacities on 
radiograph, no evidence of left atrial hypertension, and $\mathrm{PaO}_{2} / \mathrm{Fio}_{2}<300$ (acute lung injury) or $\mathrm{PaO}_{2} / \mathrm{FiO}_{2}<200$ (acute respiratory distress syndrome). Standard definitions of oxygenation index and oxygenation saturation index were applied (18).

Descriptive statistics were calculated, including means, standard deviations, medians, and interquartile ranges (IQRs) for continuous variables and frequency counts and percentages for categorical variables. Due to the potential for site-to-site heterogeneity in the reporting of sedation-related AEs, we used statistical analysis methods that allowed for clustering of observations within a site $(19,20)$. AE rates and confidence intervals were derived from generalized estimating equations using a working exchangeable correlation matrix for subjects within a site. Intraclass Correlation Coefficients (ICCs) for binary variables were estimated from an analysis of variance adjusting for age category, PRISM III-12 score, and POPC > $(21,22)$. ICCs for count and time-to-event variables were estimated from an analysis of variance (adjusting for age category, PRISM III-12 score, and POPC $>1$ ) of the deviance residuals from Poisson regression or proportional hazards models. Confidence intervals for all ICCs were constructed using Searle's method to adjust for unequal sample sizes across sites (23). Since negative values of the ICC are likely implausible, point estimates and lower $95 \%$ confidence interval limits of the ICC were truncated at zero for any calculated negative value. Data analyses were performed using SAS (Version 9.2, SAS Institute, Cary, NC).

\section{RESULTS}

A total of 2,617 intubated and mechanically ventilated patients were screened over a 7month period in the 22 PICUs. Of these, 2,149 (82\%) were ineligible, primarily because they were not intubated for acute respiratory failure. Of the 468 eligible patients, 160 (34\%) were not enrolled due to parent refusal, parent unavailability to provide written consent, language barrier, and/or staff unavailability. We prospectively collected data from the remaining 308 subjects whose parents/guardians provided consent. Clinical sites contributed data on an average of 14 subjects, with a range of four to 31 subjects.

The demographic characteristics, PRISM III-12 scores, reasons for intubation, and markers of acute lung injury severity are presented in Table 2 . The 308 subjects provided data on 4,231 PICU days, 7,191 hospital days, 2,482 ventilator days, 12,159 device days, and 2,609 central catheter days (from 222 subjects who ever had a central catheter). A total of 594

RESTORE Specified Events were reported in 308 subjects for a rate of 1.9 AEs per subject and 16.6 AEs per 100 PICU days. Fifty-four percent of subjects had at least one AE. Seven (1\%) AEs were classified as severe, $347(58 \%)$ as moderate, and $240(40 \%)$ as mild. The severe AEs were extubation failure $(n=5)$, postextubation stridor $(n=1)$, and inadequate pain management $(\mathrm{n}=1)$.

Inadequate sedation management (242 events in 93 [30\%] subjects) and inadequate pain management (173 events in 83 [26\%] subjects) were the most frequently reported events (Table 3). There were 56 (18\%) subjects who had both inadequate sedation and pain management. In patients requiring neuromuscular blockade, "assumed agitation present" was used to describe agitation at least part of the study day that $27(11 \%)$ inadequate 
sedation-management AEs occurred, while "assumed pain present" was used to describe pain at least part of the study day that $24(14 \%)$ inadequate pain-management AEs occurred. The preferential sedatives were fentanyl, morphine, and benzodiazepines. As expected and previously reported in the literature, there was a wide variation in the number, type, and dose of sedatives used across sites (24-26). Almost half (46\%) of the subjects were weaned from 25 days of continuous, intermittent, or as-needed opioids and thus considered at risk for iatrogenic withdrawal syndrome (27). Twenty-four (8\%) subjects experienced 54 episodes of clinically significant iatrogenic withdrawal. The median Withdrawal Assessment Tool-Version 1 score associated with clinically significant iatrogenic withdrawal was 6 (IQR: 4-7).

There were 20 unplanned ETT extubations in $19(6 \%)$ subjects with an event rate of 0.82 per 100 ventilator days, and 14 unplanned extubations (70\%) were followed by reintubation within $24 \mathrm{hrs}$. The median age of the 19 subjects was $1.0 \mathrm{yr}$ (IQR: 0.3-4.9). Almost all of these subjects $(95 \%, \mathrm{n}=18)$ were orally intubated. The last recorded SBS score was 0 (awake) for nine out of 16 unplanned ETT extubations (56\%) and, on average, the last sedative titration or administration of a bolus was given 73 mins before the event $(n=19$ extubations). Most events occurred with a 1:1 nurse/patient ratio (60\%), during nursing care $(55 \%)$, and with a nurse at the bedside $(75 \%)$.

There were 34 instances of postextubation stridor in $32(10 \%)$ subjects. Their median age was 1.5 yrs (IQR: 0.3-6.2). All subjects were orally intubated, most with a cuffed ETT (65\%, 20 out of 31 subjects). Steroids were used pre-extubation in seven out of 33 events (21\%), and there was a bronchoscopy for airway evaluation for five out of 33 events (15\%). No subjects were diagnosed with postextubation vocal cord paralysis. Two subjects $(6 \%)$ had a history of a difficult or traumatic intubation and three subjects (9\%) had a tracheal infection at the time of the event.

There were a total of 287 planned extubations in 268 subjects and 35 events of extubation failure before the first successful extubation (subject extubated for >24 hrs) in 28 (9\%) subjects. Thirty-five percent of subjects who had successful extubations received noninvasive ventilation. Of the 28 subjects experiencing extubation failure, 14 subjects had planned extubations, 11 had unplanned extubations, and three had multiple extubations that were both planned and unplanned. The most frequent reasons for reintubation were lower respiratory hypoxia/hypercarbia (29\%), upper airway stridor (26\%), and insufficient respiratory effort due to over sedation $(9 \%)$. Patients with extubation failure had a median age of 0.6 yrs (IQR: 0.2-3.0). Thirty-four percent of the reintubations were preceded by racemic epinephrine to prevent reintubation. Twelve out of the 35 (34\%) reintubations occurred within 30 mins of extubation (11 of these occurred after unplanned extubations), in ten of $35(29 \%)$, noninvasive positive pressure ventilation was used between extubation and reintubation, and the remaining 13 of $35(37 \%)$ were reintubated without a trial of positive pressure ventilation. At the next 08:00 time point after reintubation, the oxygenation index was 7.1 (median; IQR: $4.2-9.4, \mathrm{n}=13$ events) in those with arterial access and the oxygenation saturation index was 4.3 (median, IQR: 3.6-6.1, $\mathrm{n}=22$ events) in those without arterial access. Subjects who had an extubation failure had a longer duration of mechanical 
ventilation compared to those who did not (median [IQR]: 11.1 days [7.5-22.3] vs. 5.6 days [3.0-11.7], $p<.001)$.

Twenty (6\%) subjects experienced at least one unplanned removal of an invasive tube for a rate of 0.19 per 100 device days. The SBS score before the event was recorded for 15 events, ten $(67 \%)$ of which noted the subject to be awake or agitated (SBS $0,+1$, or +2 ). Half of these events were the unplanned removal of a nasogastric drainage tube.

Six (2\%) subjects were reported to have adjudicated VAP for an event rate of 2.41 per 1000 ventilator days. Two (1\%) subjects were reported to have adjudicated CA-BSI for an event rate of 0.77 per 1000 central catheter days. Four (1\%) subjects were reported to have Stage $2+$ pressure ulcers. The Braden $\mathrm{Q}$ was assessed for three of these subjects, all of whom were considered at risk for a pressure ulcer (Braden $\mathrm{Q}<16$ ). Two ulcers were located on the coccyx and one each on the sacrum and shoulder.

Table 3 presents the ICC estimates for the RESTORE Specified Events adjusting for age category, PRISM III-12 score, and POPC $>1$. The events with the largest ICCs included inadequate sedation management (0.130), clinically significant iatrogenic withdrawal (0.088), inadequate pain management (0.080), and postextubation stridor (0.078). Figure 1 demonstrates the site-to-site variability of the inadequate sedation management rate, the event with both the highest rate of occurrence and the highest ICC.

Characteristics related to the hospital course are presented in Table 4. Overall, the ICCs for the hospital course variables tended to be lower than those for the most frequently occurring RESTORE Specified Events.

\section{DISCUSSION}

Our results characterize AEs among a large population of critically ill pediatric patients intubated for respiratory failure. We estimated the rate and site-to-site heterogeneity of prospectively collected sedation-related AEs among the 22 participating sites. Sedation is an integral part of PICU care and is needed to facilitate treatment and prevent complications related to anxiety or movement.

There were a large number of subjects with inadequate pain or sedation management, comprising $70 \%$ of reported events. Differentiating between pain and agitation is difficult in this population. There is no universal definition or reported incidence of inadequate pain and sedation management in pediatric patients. Standardized measurement tools, definitions, and reporting structure of AEs were used; however, there was no standardized attempt to manage sedation. This manuscript represents the first attempt to estimate the incidence of inadequate pain and sedation management in mechanically ventilated pediatric patients. Unplanned extubations in pediatric patients have been reported in a number of clinical settings. In these studies, the unplanned extubation rate ranged from 0.19 to 1.2 per 100 ventilator days (28-33). The unplanned extubation rate in our subjects was 0.82 per 100 ventilator days, which compares favorably with the published pediatric critical care rates. Reported factors associated with unplanned extubation include a higher patient-to-nurse ratio $(28,29)$ and younger patient age $(31,32)$. For most of the unplanned extubation events 
in our subjects, there was a 1:1 nurse/patient ratio and most events occurred with a nurse at the bedside and during nursing cares, and half of these subjects were under $1 \mathrm{yr}$ of age.

Extubation failure, with reintubation within $24 \mathrm{hrs}$ of extubation, in pediatric patients has been reported from a rate of $4.1 \%$ to $14 \%(32-35)$. These rates represent a diverse patient population. Our extubation failure rate of $8.9 \%$ falls within this range. The reported etiologies of extubation failure include lower $\mathrm{PaO}_{2}$, cardiorespiratory failure, and unplanned extubations. Our patients with extubation failure had a longer length of mechanical ventilation than those without. The overall incidences of postextubation stridor $(10 \%)$ and extubation failure (9\%) were low, although $26 \%$ of patients who had an extubation failure experienced upper airway stridor.

It is difficult to estimate the extent to which random or systematic error among the adjudicators might have attenuated our ability to accurately detect VAP events (36). Our VAP rate of 2.41 per 1000 ventilator days is similar to the most recent 2009 National Healthcare Safety Network pooled mean of 2.3 per 1000 ventilator days in pediatric critical care medical units (37). Not all RESTORE clinical sites had a specific adjudication process before beginning data collection.

Our rate of $0.77 \mathrm{CA}-\mathrm{BSI}$ per 1000 central catheter days is lower than many reported rates. The National Healthcare Safety Network reported a pooled mean of 3.0 CA-BSI per 1,000 central catheter days in the evaluation of 314,306 central catheter days in pediatric medical surgical critical care units (37). Our rate of Stage $2+$ pressure ulcers $(1.4 \%)$ is much lower than the $27 \%$ that has been previously reported (17).

A significant advantage of multicenter vs. single-center studies is the ability to address siteto-site heterogeneity in outcomes. We found moderate variation in event reporting even with clear operational definitions, consistent training of personnel at each site, external site monitoring of events, and adjustment for age category, PRISM III-12, and POPC >1. For four RESTORE Specified Events, inadequate sedation and pain management, clinically significant iatrogenic withdrawal, and postextubation stridor, the ICCs, measuring the proportion of variation in outcome attributable to the natural variation between sites rather than between subjects within sites, ranged from $7.8 \%$ to $13.0 \%$. We also found that the ICCs for our hospital course variables tended to be smaller than those of the RESTORE Specified Events, perhaps because length of stay is dependent on a variety of patient-related factors.

These data are limited in that they represent subjects enrolled in the baseline phase of a clinical study and thus do not represent the entire population of intubated PICU patients. There was no attempt to analyze data in relation to institutional-specific practice patterns, such as compliance to infection control guidelines, which may affect the VAP and BSI rates.

Ensuring the validity and reproducibility of AE measurement is crucial to the quality of the data. For many of the AEs reported in this paper, no reference standards exist and adjudication procedures were used to enhance internal and external validity. 


\section{CONCLUSIONS}

Our large pediatric critical care study describes sedation-related AEs in a population of intubated and mechanically ventilated pediatric patients with acute respiratory failure from 22 PICUs. The combined use of multiple processes, including standardized operational definitions, site training, monitored reporting structure, and on-site monitoring, all contributed to providing consistent AE data reporting from multiple PICUs. There were a high proportion of patients with inadequate pain or sedation management. We have described patients who experienced airway compromise by an unplanned extubation, postextubation stridor, and/or extubation failure. AE identification has been a focus of increased interest, particularly over the last decade. In spite of this, however, we found moderate site-to-site heterogeneity for some AEs. Understanding the frequency of these events is essential to improving the quality of care and may facilitate the development of prevention strategies in critically ill children.

\section{ACKNOWLEDGMENTS}

We thank the following 22 clinical sites that participated in the baseline phase of the RESTORE clinical trial: 1) Advocate Hope Children's Hospital; 2) Children's Hospital and Research Center at Oakland; 3) Children's Hospital at UCSF Medical Center; 4) Children's Hospital of Alabama; 5) Children's Hospital of Philadelphia; 6) Children's Memorial Hospital, Chicago; 7) Children's Mercy Hospital, Kansas City; 8) Connecticut Children's Medical Center; 9) C. S. Mott Children's Hospital of the University of Michigan; 10) Dartmouth-Hitchcock Medical Center; 11) Doernbecher Children's Hospital; 12) Duke Children's Hospital and Health Center; 13) Johns Hopkins Children's Center; 14) Lucile Salter Packard Children's Hospital at Stanford; 15) Monroe Carell Jr Children's Hospital at Vanderbilt; 16) Nemours/A I DuPont Hospital for Children; 17) Primary Children's Medical Center, Salt Lake City; 18) St. Louis Children's Hospital; 19) UMass Memorial Children's Medical Center; 20) University of California Davis Medical Center; 21) University of Maryland Hospital for Children; and 22) Yale-New Haven Children's Hospital.

Supported, in part, by the National Institutes of Health, the National Heart, Lung, and Blood Institute, and the National Institute of Nursing Research: HL086622 and HL086649.

\section{REFERENCES}

1. Lubisch N, Roskos R, Sattler SM. Improving outcomes in pediatric procedural sedation. Jt Comm J Qual Patient Saf. 2008; 34:192-195. [PubMed: 18468355]

2. Rothschild JM, Keohane CA, Cook EF, et al. A controlled trial of smart infusion pumps to improve medication safety in critically ill patients. Crit Care Med. 2005; 33:533-540. [PubMed: 15753744]

3. Garrouste-Orgeas M, Timsit JF, Vesin A, et al. Selected medical errors in the intensive care unit: Results of the IATROREF study: Parts I and II. Am J Respir Crit Care Med. 2010; 181:134-142. [PubMed: 19875690]

4. Agarwal S, Classen D, Larsen G, et al. Prevalence of adverse events in pediatric intensive care units in the United States. Pediatr Crit Care Med. 2010; 11:568-578. [PubMed: 20308932]

5. Fiser DH, Long N, Roberson PK, et al. Relationship of pediatric overall performance category and pediatric cerebral performance category scores at pediatric intensive care unit discharge with outcome measures collected at hospital discharge and 1- and 6-month follow-up assessments. Crit Care Med. 2000; 28:2616-2620. [PubMed: 10921604]

6. Pollack MM, Patel KM, Ruttimann UE. PRISM III: An updated Pediatric Risk of Mortality score. Crit Care Med. 1996; 24:743-752. [PubMed: 8706448]

7. Merkel SI, Voepel-Lewis T, Shayevitz JR, et al. The FLACC: A behavioral scale for scoring postoperative pain in young children. Pediatr Nurs. 1997; 23:293-297. [PubMed: 9220806]

8. Manworren RC, Hynan LS. Clinical validation of FLACC: Preverbal patient pain scale. Pediatr Nurs. 2003; 29:140-146. [PubMed: 12723828] 
9. Wong, DL.; Hockenberry-Eaton, M.; Wilson, D., et al. Whaley and Wong's Nursing Care of Infants and Children. St. Louis, MO: Mosby; 1999.

10. Solodiuk J, Curley MA. Pain assessment in nonverbal children with severe cognitive impairments: The Individualized Numeric Rating Scale (INRS). J Pediatr Nurs. 2003; 18:295-299. [PubMed: 12923744]

11. Curley MA, Harris SK, Fraser KA, et al. State Behavioral Scale: A sedation assessment instrument for infants and young children supported on mechanical ventilation. Pediatr Crit Care Med. 2006; 7:107-114. [PubMed: 16446601]

12. Franck LS, Harris SK, Soetenga DJ, et al. The Withdrawal Assessment Tool-1 (WAT-1): An assessment instrument for monitoring opioid and benzodiazepine withdrawal symptoms in pediatric patients. Pediatr Crit Care Med. 2008; 9:573-580. [PubMed: 18838937]

13. Langley JM, Bradley JS. Defining pneumonia in critically ill infants and children. Pediatr Crit Care Med. 2005; 6:S9-S13. [PubMed: 15857566]

14. Centers for Disease Control and Prevention: National Healthcare Safety Network Manual. [Accessed January 5, 2011] Available at: http://www.cdc.gov/nhsn/PDFs/pscManual/ 17 pscNosInfDef_current.pdf.

15. Cook D, Walter S, Freitag A, et al. Adjudicating ventilator-associated pneumonia in a randomized trial of critically ill patients. J Crit Care. 1998; 13:159-163. [PubMed: 9869541]

16. National Pressure Ulcer Advisory Panel: Pressure Ulcer Definitions and Descriptions 2007. Available at http://www.npuap.org.

17. Curley MA, Razmus IS, Roberts KE, et al. Predicting pressure ulcer risk in pediatric patients: The Braden Q Scale. Nurs Res. 2003; 52:22-33. [PubMed: 12552172]

18. Thomas NJ, Shaffer ML, Willson DF, et al. Defining acute lung disease in children with the oxygenation saturation index. Pediatr Crit Care Med. 2010; 11:12-17. [PubMed: 19561556]

19. Hayes, RJ.; Moulton, LH. Cluster Randomised Trials. Boca Raton, FL: Chapman and Hall/CRC Press; 2009.

20. Donner, A.; Klar, N. Design and Analysis of Cluster Randomization Trials in Health Research. London, UK: Hodder Arnold; 2000.

21. Ridout MS, Demétrio CG, Firth D. Estimating intraclass correlation for binary data. Biometrics. 1999; 55:137-148. [PubMed: 11318148]

22. Hade EM, Murray DM, Pennell ML, et al. Intraclass correlation estimates for cancer screening outcomes: Estimates and applications in the design of group-randomized cancer screening studies. J Natl Cancer Inst Monogr. 2010; 40:97-103. [PubMed: 20386058]

23. Ukoumunne OC. A comparison of confidence interval methods for the intraclass correlation coefficient in cluster randomized trials. Stat Med. 2002; 21:3757-3774. [PubMed: 12483765]

24. Rhoney DH, Murry KR. National survey on the use of sedatives and neuromuscular blocking agents in the pediatric intensive care unit. Pediatr Crit Care Med. 2002; 3:129-133. [PubMed: 12780981]

25. Twite MD, Rashid A, Zuk J, et al. Sedation, analgesia, and neuromuscular blockade in the pediatric intensive care unit: Survey of fellowship training programs. Pediatr Crit Care Med. 2004; 5:521-532. [PubMed: 15530187]

26. Marx CM, Rosenberg DI, Ambuel B, et al. Pediatric intensive care sedation: Survey of fellowship training programs. Pediatrics. 1993; 91:369-378. [PubMed: 8424013]

27. Tobias JD. Tolerance, withdrawal, and physical dependency after long-term sedation and analgesia of children in the pediatric intensive care unit. Crit Care Med. 2000; 28:2122-2132. [PubMed: 10890677]

28. Ream RS, Mackey K, Leet T, et al. Association of nursing workload and unplanned extubations in a pediatric intensive care unit. Pediatr Crit Care Med. 2007; 8:366-371. [PubMed: 17545927]

29. Marcin JP, Rutan E, Rapetti PM, et al. Nurse staffing and unplanned extubation in the pediatric intensive care unit. Pediatr Crit Care Med. 2005; 6:254-257. [PubMed: 15857520]

30. Popernack ML, Thomas NJ, Lucking SE. Decreasing unplanned extubations: Utilization of the Penn State Children's Hospital Sedation Algorithm. Pediatr Crit Care Med. 2004; 5:58-62. [PubMed: 14697110] 
31. Sadowski R, Dechert RE, Bandy KP, et al. Continuous quality improvement: Reducing unplanned extubations in a pediatric intensive care unit. Pediatrics. 2004; 114:628-632. [PubMed: 15342831]

32. Kurachek SC, Newth CJ, Quasney MW, et al. Extubation failure in pediatric intensive care: A multiple-center study of risk factors and outcomes. Crit Care Med. 2003; 31:2657-2664. [PubMed: 14605539]

33. Baisch SD, Wheeler WB, Kurachek SC, et al. Extubation failure in pediatric intensive care incidence and outcomes. Pediatr Crit Care Med. 2005; 6:312-318. [PubMed: 15857531]

34. Fontela PS, Piva JP, Garcia PC, et al. Risk factors for extubation failure in mechanically ventilated pediatric patients. Pediatr Crit Care Med. 2005; 6:166-170. [PubMed: 15730603]

35. Farias JA, Alía I, Retta A, et al. An evaluation of extubation failure predictors in mechanically ventilated infants and children. Intensive Care Med. 2002; 28:752-757. [PubMed: 12107682]

36. Venkatachalam V, Hendley JO, Willson DF. The diagnostic dilemma of ventilator-associated pneumonia in critically ill children. Pediatr Crit Care Med. 2011; 12:286-296. [PubMed: 21037503]

37. Edwards JR, Peterson KD, Mu Y, et al. National Healthcare Safety Network (NHSN) report: Data summary for 2006 through 2008, issued December 2009. Am J Infect Control. 2009; 37:783-805. [PubMed: 20004811] 


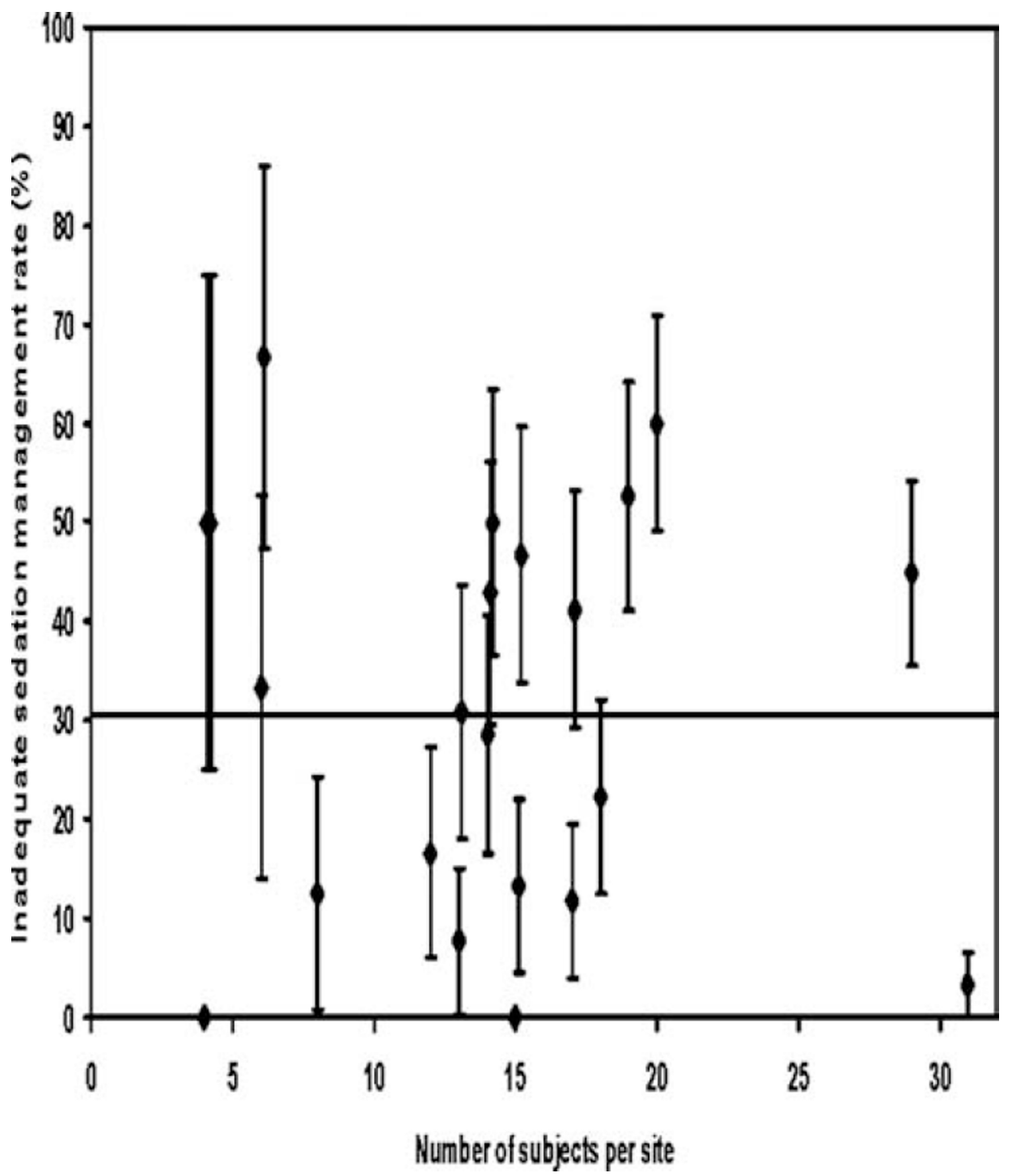

Figure 1.

Inadequate sedation management rate per clinical site. Two sites reported no subjects with inadequate sedation management. The error bars represent \pm 1 standard error. The horizontal line at $30.7 \%$ represents the inadequate sedation management rate across all clinical sites, adjusted for site. 


\section{Table 1}

\section{RESTORE Specified Events operational definitions}

Inadequate pain management: Pain score $>4$ (or "assumed pain present" in patients receiving neuromuscular blockade) for 2 consecutive hours not related to a planned extubation attempt

Inadequate sedation management: Agitation defined by a State Behavioral Scale score $>0$ (or "assumed agitation present" in patients receiving neuromuscular blockade) for 2 consecutive hours not related to a planned extubation attempt

Clinically significant iatrogenic withdrawal: In patients weaning from $>5$ days of continuous infusion or round-the-clock narcotics, any patient receiving rescue therapy (defined as an opioid or benzodiazepine bolus or an increase in opioid or benzodiazepine infusion) to manage an increase in Withdrawal Assessment Tool-Version 1 symptoms after the start of weaning and not for treatment of new pain or sedation needs

Unplanned endotracheal tube extubation: Unplanned extubation

Postextubation stridor with chest-wall retractions at rest: Stridor (defined as a high-pitched or harsh inspiratory noise) with chest-wall retractions after endotracheal tube extubation

Extubation failure: Reintubation within $24 \mathrm{hrs}$

Unplanned removal of any invasive tube: Unplanned removal of any invasive tube (e.g., arterial access, central venous access, peripheral venous access, nasogastric drainage tube, bladder catheter, chest tube, "other" tube)

Ventilator-associated pneumonia: Adjudicated using National Healthcare Safety Network definition (14)

Catheter-associated bloodstream infection: Adjudicated using National Healthcare Safety Network definition (14)

Stage 2+ pressure ulcers: Stage 2+ (or worse) partial thickness loss of skin layers involving epidermis and possibly penetrating into but not through dermis. May present as blistering with erythema and/or induration; wound base moist and pink; painful; free from necrotic tissue. 
Table 2

Characteristics of RESTORE baseline subjects at admission to the intensive care unit $(\mathrm{n}=308)$

\begin{tabular}{|c|c|}
\hline Characteristics & Values \\
\hline Age in years, mean \pm sd & $4.4 \pm 5.2$ \\
\hline \multirow[t]{3}{*}{$a$} & 56 \\
\hline & 15 \\
\hline & 29 \\
\hline Male, $\%$ & 54 \\
\hline \multicolumn{2}{|l|}{ Race, $\%$} \\
\hline White & 72 \\
\hline Black or African American & 19 \\
\hline Multiracial & 4 \\
\hline Asian & 3 \\
\hline Other & 1 \\
\hline Hispanic, \% & 17 \\
\hline Pediatric Cerebral Performance Category $>1, \%$ & 29 \\
\hline Pediatric Overall Performance Category $>1, \%$ & 31 \\
\hline Pediatric Risk of Mortality III-12 score, ${ }^{b}$ median (IQR) & $6(2.5-12)$ \\
\hline Risk of mortality, median (IQR) & $3 \%(1 \%-13 \%)$ \\
\hline \multicolumn{2}{|l|}{ Primary reason for mechanical ventilation, $\%$} \\
\hline Pneumonia & 36 \\
\hline Bronchiolitis & 27 \\
\hline Acute respiratory failure related to sepsis & 9 \\
\hline Asthma or reactive airway disease & 6 \\
\hline Aspiration pneumonia & 6 \\
\hline Pulmonary edema & 5 \\
\hline Acute respiratory failure post bone marrow transplant & 2 \\
\hline Other & 9 \\
\hline Worst oxygenation index on day of intubation, ${ }^{c}$ median (IQR) & $9.4(5.4-19.7)$ \\
\hline Worst oxygenation saturation index on day of intubation, ${ }^{d}$ median (IQR) & $7.0(5.2-12.4)$ \\
\hline \multicolumn{2}{|l|}{ IQR, interquartile range ( 25 th percentile-75th percentile). } \\
\hline \multicolumn{2}{|l|}{$a_{\text {Ten }}(3 \%)$ subjects were $<30$ days old; } \\
\hline \multicolumn{2}{|l|}{$\begin{array}{l}b_{\text {Pediatric Risk of Mortality III using da }} \\
c_{\mathrm{n}=137 \text { subjects with arterial access; }}\end{array}$} \\
\hline
\end{tabular}




\begin{tabular}{|c|c|c|c|c|}
\hline Inadequate sedation management & 242 & 93 & $30.7 \%(23.0 \%-39.6 \%)$ & $0.130(0.052-0.279)$ \\
\hline Clinically significant iatrogenic withdrawal & 54 & 24 & $8.7 \%(5.2 \%-14.3 \%)$ & $0.088(0.024-0.218)$ \\
\hline $\begin{array}{l}\text { Unplanned endotracheal tube extubation (per } 100 \\
\text { ventilator days) }\end{array}$ & 20 & 19 & $0.82(0.55-1.23)$ & $0.000(0.000-0.038)$ \\
\hline Postextubation stridor with chest-wall retractions at rest & 34 & 32 & $10.3 \%(6.3 \%-16.4 \%)$ & $0.078(0.018-0.203)$ \\
\hline Extubation failure/reintubation within $24 \mathrm{hrs}$ & 35 & 28 & $8.9 \%(5.9 \%-13.3 \%)$ & $0.017(0.000-0.102)$ \\
\hline $\begin{array}{l}\text { Unplanned removal of any invasive tube (per } 100 \text { device } \\
\text { days) }\end{array}$ & 24 & 20 & $0.19(0.11-0.32)$ & $0.005(0.000-0.081)$ \\
\hline $\begin{array}{l}\text { Ventilator-associated pneumonia (per } 1000 \text { ventilator } \\
\text { days) }\end{array}$ & 6 & 6 & $2.41(1.00-5.80)$ & $0.000(0.000-0.073)$ \\
\hline $\begin{array}{l}\text { Catheter-associated bloodstream infection (per } 1000 \\
\text { central catheter days) }\end{array}$ & 2 & 2 & $0.77(0.20-2.91)$ & $0.064(0.008-0.182)$ \\
\hline Stage $2+$ pressure ulcers & 4 & 4 & $1.4 \%(0.5 \%-4.4 \%)$ & $0.048(0.000-0.155)$ \\
\hline
\end{tabular}

and Pediatric Overall Performance Category $>1$. 
Table 4

Course of illness of RESTORE baseline subjects $(\mathrm{n}=308)$

\begin{tabular}{|c|c|c|}
\hline Outcome & $\begin{array}{l}\text { Median (Interquartile } \\
\text { Range) or } \\
\text { n }(\%)\end{array}$ & $\begin{array}{c}\text { Intraclass Correlation } \\
\text { Coefficient }^{a} \\
\text { (95\% Confidence Interval) }\end{array}$ \\
\hline Duration of mechanical ventilation (days) & $6.0(3.3-12.3)$ & $0.011(0.000-0.092)$ \\
\hline Pediatric intensive care unit length of stay (days) $b$ & $9.6(5.7-17.0)$ & $0.001(0.000-0.074)$ \\
\hline Hospital length of stay (days) $)^{b}$ & $15(9-28)$ & $0.048(0.000-0.154)$ \\
\hline 28-day mortality (in hospital) & $13(4)$ & $0.000(0.000-0.050)$ \\
\hline Subjects ever meeting acute lung injury criteria & $115(37)$ & $0.069(0.012-0.188)$ \\
\hline Subjects ever meeting acute respiratory distress syndrome criteria & $85(28)$ & $0.040(0.000-0.141)$ \\
\hline
\end{tabular}

${ }^{a}$ Intraclass correlation coefficient measuring site-to-site heterogeneity after adjustment for age category, Pediatric Risk of Mortality III-12 score, and Pediatric Overall Performance Category $>1$;

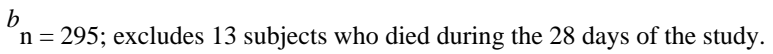

